\title{
How the Virus Outsmarts the Host: Function and Structure of Cytomegalovirus MHC-I-Like Molecules in the Evasion of Natural Killer Cell Surveillance
}

\author{
Maria Jamela Revilleza, ${ }^{1}$ Rui Wang, ${ }^{1}$ Janet Mans, ${ }^{2,3}$ Manqing Hong, ${ }^{1}$ \\ Kannan Natarajan, ${ }^{1}$ and David H. Margulies ${ }^{1}$ \\ ${ }^{1}$ Molecular Biology Section, Laboratory of Immunology, NIAID, National Institutes of Health, Bethesda, MD 20892-1892, USA \\ ${ }^{2}$ Department of Virology, University of the Witwatersrand, Johannesburg 2050, South Africa \\ ${ }^{3}$ Department of Medical Virology, University of Pretoria, Pretoria 0001, South Africa
}

Correspondence should be addressed to David H. Margulies, dhm@nih.gov

Received 25 February 2011; Accepted 28 March 2011

Academic Editor: John E. Coligan

Copyright (c) 2011 Maria Jamela Revilleza et al. This is an open access article distributed under the Creative Commons Attribution License, which permits unrestricted use, distribution, and reproduction in any medium, provided the original work is properly cited.

Natural killer (NK) cells provide an initial host immune response to infection by many viral pathogens. Consequently, the viruses have evolved mechanisms to attenuate the host response, leading to improved viral fitness. One mechanism employed by members of the $\beta$-herpesvirus family, which includes the cytomegaloviruses, is to modulate the expression of cell surface ligands recognized by NK cell activation molecules. A novel set of cytomegalovirus (CMV) genes, exemplified by the mouse m145 family, encode molecules that have structural and functional features similar to those of host major histocompatibility-encoded (MHC) class I molecules, some of which are known to contribute to immune evasion. In this review, we explore the function, structure, and evolution of MHC-I-like molecules of the CMVs and speculate on the dynamic development of novel immunoevasive functions based on the MHC-I protein fold.

\section{Introduction}

Mammals are susceptible to a wide range of infectious agents, including, but not limited to, viruses, bacteria, and protozoan parasites. While many microbes cause debilitating illnesses, are responsible for much morbidity and mortality worldwide, and garner much of the public's attention, other organisms stealthily invade their hosts, establish lifelong infection, and remarkably, cause little or no symptoms in healthy individuals. CMVs are examples of microbes that establish asymptomatic, latent, and lifelong infections, revealing themselves only when the host's immune system is compromised. Virus survival in the face of an intact immune system is accomplished through subversion of antiviral immunity by an arsenal of virally encoded proteins, termed immunoevasins, that specifically target key molecular recognition steps necessary for an immune response. The interplay of evolutionary diversification of immunoevasins with the defense mechanisms of the host results in a dynamic balance permitting the survival of both the host and the infectious organism. Among the many viral infections of fundamental interest that have been well studied are the species-specific large DNA viruses of the $\beta$-herpesvirus family, of which the CMVs are representative members $[1,2]$. The human CMV (HCMV) as well as its murine relative (MCMV) [3] and other species such as the guinea pig (GPCMV) [4], rhesus (RhCMV) [5-9], and chimpanzee (CCMV) [10, 11] have been the subject of recent studies designed to understand not only the basic genetics, biochemistry, and biology of these complex organisms but also to discern the immune responses of their hosts, with an ultimate goal of developing effective vaccines to alleviate pathogenic effects of the viruses. MCMV infection is a model for HCMV infection in humans, because of similarities in viral life cycle, genome structure, and host immune response [12-15]. These viruses exhibit similarities in the life cycle of acute infection, persistence and 
latent infection or superinfection, and reactivation under conditions of immune suppression $[8,16]$. The subject of this review is a structural, genetic, and functional analysis of a set of genes and their encoded glycoproteins that have been adapted by MCMV to assure the continued survival of the virus. Because of the structural similarities of these encoded proteins to MHC-I and other MHC-I-like molecules of the host, we argue that these molecules were derived from lateral (horizontal) genetic transmission from host to virus.

HCMV is a serious and opportunistic pathogen that affects $45-100 \%$ of the adult population. Seroprevalence is influenced by age, race and ethnicity, sex, and socioeconomic status where frequency of infection is highest in urban areas [17]. Primary infections are usually asymptomatic in healthy individuals but can cause significant morbidity in immunocompromised patients such as those with AIDS or cancer, and in individuals undergoing therapeutic immunosuppression in the course of solid organ transplantation. Congenital infection resulting from primary maternal infection that has a rate of $1-4 \%$ is also a major concern, leading to long-term sequelae such as neurodevelopmental disabilities, including mental retardation and sensorineural hearing loss [18].

\section{Background}

2.1. The Immune Response to CMV Infection. Mammalian cells possess sophisticated mechanisms that telegraph their health status to the cell surface for recognition by inflammatory and immune cells. The vertebrate host responds to CMV infection using the full battery of specialized cells of the immune system: NK-cells, B cells, and T cells of both cytolytic $\left(\mathrm{CD}^{+}\right)$and helper $\left(\mathrm{CD}^{+}\right)$lineages. Aspects of both acute and chronic CMV disease may be controlled by antibodies, NK, and other cells of the innate immune system, as well as by $\mathrm{CD}^{+}$and $\mathrm{CD}^{+} \mathrm{T}$ cells. Such cells of the immune system can either directly kill the virus-infected cells or produce bioactive molecules that exert direct and indirect effects on the innate and adaptive arms of the immune response. Two main cellular mechanisms alert the immune system to an infected or stressed state: NK-cell and T-cell recognition and activation.

During viral infection, NK-cells offer an important first line of defense that limits viral expansion at a time when specific immunity has not yet fully developed. But the virus has evolved countermeasures to balance this formidable NK surveillance [19] (see Figure 1). Following the initial NK response, the host develops adaptive $\mathrm{CD}^{+}$and $\mathrm{CD}^{+} \mathrm{T}$ cell responses [20-22].

2.2. Viral Evasins. Viruses have two major life cycle advantages that allow them to counter the host's immune response: their rapid generation time permits them to accumulate genetic variants that allow them to subvert the immune response, and viruses with large genomes have the capacity to devote extensive amounts of genetic material to functions that may provide even slight evolutionary advantage. As a group, the CMV have genomes that are colinear as in the case of MCMV and HCMV, that may be as large as

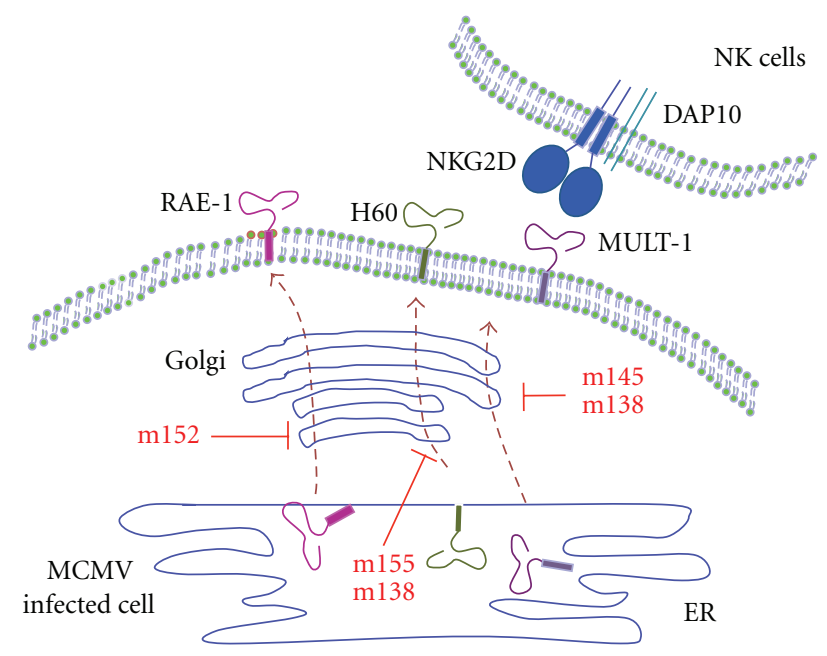

(a)

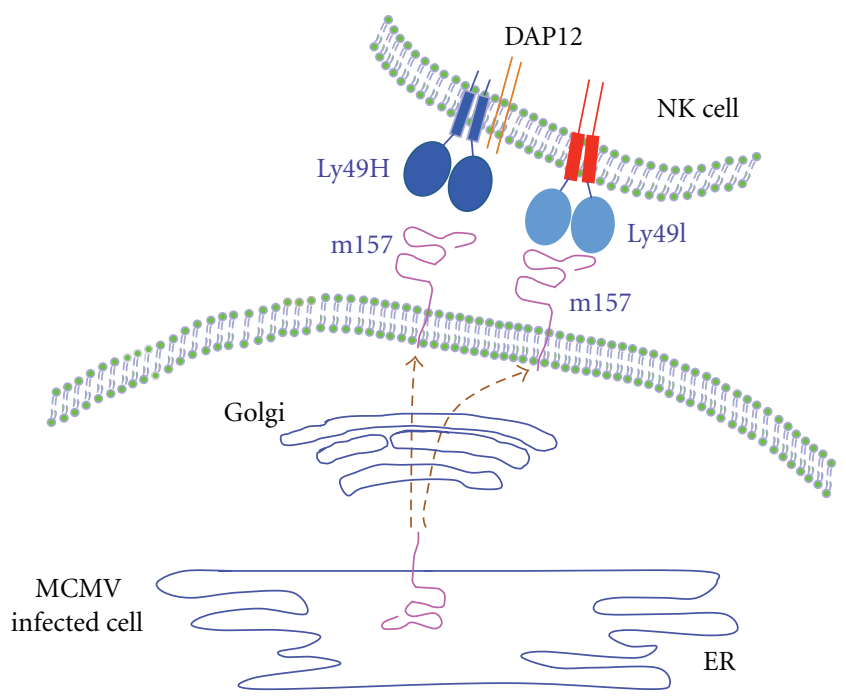

(b)

Figure 1: MCMV-encoded proteins disrupt NK-cell recognition of infected cells. During MCMV infection, the surface expression of the stress-induced molecules, ligands for NKG2D, is downregulated: m152 downregulates all isoforms of RAE-1, m145 and m155 interfere with $\mathrm{H} 60$ and MULT-1, respectively, and m138 downregulates H60, MULT-1, and RAE-1ع (a). m157 binds both inhibitory NK receptor, Ly49I, and activating NK receptor, Ly49H (b).

$230 \mathrm{~kb}$, and that encode as many as 170 open reading frames (ORFs), of which about one-third is required for essential viral functions. About half of the identified genes in MCMV have HCMV homologues $[23,24]$. Although the genetic and functional analysis of all of these genes has not yet been performed, studies of many of them indicate a role in curtailing NK-cell recognition of the virus-infected cell or in interfering with antigen processing and presentation to $\mathrm{CD}^{+} \mathrm{T}$ cells. Of particular interest to our studies of MHC-I-like molecules of the virus is the m145 family of genes (m17, m145 to $\mathrm{m} 158$ ), several of which have been shown to contribute to viral fitness. (Originally denoted the m145 family, current BLAST [25] searches of the protein database identify their 
encoded proteins as members of the "m157 superfamily.") Remarkably, most of these genes map to the extreme right end of the MCMV genome while the more highly conserved essential functions of the virus map to the center. Also, another set of genes, some of which play a similar role immunoevasion, map to the extreme left of the MCMV genome. These are known as the $\mathrm{m} 02$ family (genes $\mathrm{m} 02$ to $\mathrm{m} 16$ ) and some evidence suggests that they can impair T-cell receptormediated recognition of MHC-I/peptide complexes that lead to $\mathrm{CD} 8^{+} \mathrm{T}$-cell activation $[26,27]$.

2.3. NK Receptors in Viral Infection. During the early stages of MCMV infection, the host immune response is dominated by NK-cell activation and the resulting cytolysis of virusinfected cells. The activation of NK-cells is regulated by a balance of signals delivered through activating or inhibitory receptors. These surface molecules either bind classical MHC-I molecules or MHC-I homologues and are classified into two families: C-type lectin-like (Ly49, NKG2D and CD94/NKG2) and immunoglobulin-like (KIRs and LIRs) as reviewed elsewhere [28-30].

2.4. NKG2D. The infected cell initiates a complex stress response, leading to increased cell surface production of a spectrum of molecules including MICA or MICB, and members of the ULBP family in the human [31-34], or RAE-1 $(\alpha, \beta, \gamma, \delta, \varepsilon)$, MULT-1, and H60 in the mouse [3539]. These MHC-I-like stress-induced cell surface molecules are ligands for the NK-cell activation receptor, NKG2D, the best characterized NK activating receptor. NKG2D lacks a signaling motif of its own, and thus requires association with either the DAP10 or DAP12 adapter molecules [40]. In the mouse, NKG2D Short pairs with either DAP10 or DAP12 [41, 42], while NKG2D Long interacts exclusively with DAP10. Human NKG2D, by contrast, only has the L isoform and thus interacts exclusively with DAP10 [43]. The direct interaction of NKG2D with any of the NKG2D ligands activates the NK-cell and initiates its cytokine and cytolytic program, resulting in the killing of the virus-infected cell.

To counter host NK surveillance, the virus has evolved strategies to attenuate the host cell expression of the NKG2D ligands, which it accomplishes through the expression of some m145 family members early in infection. In particular, the $\mathrm{m} 152, \mathrm{~m} 145$, and $\mathrm{m} 155$ glycoproteins, as well as the unrelated $\mathrm{m} 138$, each downregulates one or more NKG2D ligands. m152, encoding the gp40 glycoprotein, not only controls the surface expression of classical MHC-I, but also downregulates surface expression of RAE-1 molecules. Although this regulatory function of $\mathrm{m} 152$ has been recognized for several years $[44,45]$, evidence for direct interaction of m152 with RAE-1 has only been demonstrated recently. Studies show binding of m152 with RAE-1 isoforms $\beta, \gamma$, and $\delta$ and establish a relationship between the effectiveness of RAE-1 attenuation with the intrinsic affinity of the m152/RAE-1 interaction [46]. In a manner similar to that of the m152/RAE-1 interaction, the m145-encoded glycoprotein downmodulates the expression of MULT-1 [47], and m155 blocks H60 surface expression [48]. m138, originally considered a viral Fc receptor, also regulates both

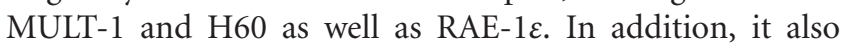
affects B7-1 (CD80) expression on dendritic cells (DCs) which impairs DC stimulation of CTLs [49]. The functions of these MCMV genes have been established in part by the judicious exploitation of deletion viruses such as the $\Delta \mathrm{m} 152$ mutant, that clearly fails to downregulate both MHC-I and RAE- $1[45,50]$, the $\Delta \mathrm{m} 138$ mutant that is deficient in H60 and MULT-1 regulation, and the $\Delta \mathrm{m} 155$ virus that attenuates the NK response in vivo and partially restores $\mathrm{H} 60$ expression on virus-infected cells [48].

The intriguing structural question raised by the paired interactions of members of the m145 family with NKG2D ligands is how precisely do these viral MHC-I-like molecules function. The high-resolution X-ray crystallographic structures of several of these viral MHC-I-like molecules are now known. In addition, the structures of some of the NKG2D ligands have been determined. These structures offer further insight not only into the function of the viral MHC-I-like molecules, but also into their evolution.

2.5. Ly49 Receptors. Major advances in our understanding of the role of NK receptors in the immune response to viral infection derived from studies of the Ly49 family in the mouse and of the KIR family in the human. These are cell surface receptors, expressed primarily on NK-cells, that interact either with host classical MHC-I molecules, or, in several notable examples, with virus-encoded ligands. The Ly49 family members are either inhibitory (such as Ly49A, Ly49C, or Ly49I), or activating (such as Ly49H or Ly49P). Similar functions are contributed by the KIRDL inhibitory receptors and the KIRDS activating receptors in the human, but our discussion will be confined to the mouse molecules.

The inhibitory receptors, with Ly49A serving as the prototype, recognize classical MHC-I on host cells, and thus deliver a tonic inhibitory signal to the NK-cell, through their cytoplasmic immunoreceptor tyrosine-based inhibition motifs (ITIMs). With decreased MHC-I expression on the virus-infected cell, the strength of the inhibitory signal decreases, and concurrent activating signals dominate, leading to lysis of the virus-infected cell. Such a mechanism, the basis of the missing self-hypothesis [51] has been wellcharacterized for the interaction of Ly49A with its MHCI ligand $\mathrm{H}-2 \mathrm{D}^{\mathrm{d}}[52,53]$. The importance of interactions of Ly49A and other inhibitory receptors with their MHC-I ligands in NK-cell education or licensing has also recently been explored [54, 55].

Some activating receptors such as $\mathrm{Ly} 49 \mathrm{H}$, in contrast to NKG2D, which exploits stress-induced ligands, do not have known self-MHC-I ligands, but instead interact strongly with some CMV-encoded molecules. Ly49H is expressed in MCMV-resistant mouse strains and binds a viral member of the m145 family, m157, which is expressed at the cell surface as a glycophosphatidylinositol (GPI)-linked glycoprotein early in infection. Ly49H deficient mice are MCMV sensitive, and transgenic expression of $\mathrm{Ly} 49 \mathrm{H}$ confirms that this activating receptor alone can account for viral resistance. In mouse strains susceptible to MCMV infection such as 
$129 / \mathrm{J}$, there is no Ly49H gene, but rather one encoding an inhibitory receptor Ly491 ${ }^{129}$, that interacts strongly with m157 [56, 57]. Thus, it would appear that m157 evolved initially in the setting of hosts that expressed Ly49I-like activities, resulting in improved viral survival. As the virus became more virulent, mouse evolution settled on the solution of shuffling the Ly49I-binding activity (residing in its extracellular domain) onto the signaling module of an activating receptor and thus became $\mathrm{Ly} 49 \mathrm{H}$, conferring resistance to viruses that express $\mathrm{m} 157$ [58]. In experiments designed to examine the evolution of virus resistance to host NK activity, it was shown that when MCMV is passaged repeatedly through resistant $\mathrm{Ly}_{4} 9 \mathrm{H}^{+}$mice, m157 mutations accumulate rapidly, permitting the virus to escape the NK immunosurveillance due to Ly49H [59]. Recent studies of a variety of naturally occurring $\mathrm{m} 157$ variants indicate that many are incapable of binding Ly49H (from C57BL/6), but can interact with Ly49C inhibitory receptors from several different strains [60]. Thus, the effects of the differential interactions of Ly49 activating and inhibitory NK receptors on the evolution of viral MHC-like ligands, such as m157, may prove to be even more complex than previously thought.

There are some mouse strains that lack Ly49H but are resistant to MCMV infection through other NK-cellmediated mechanisms. An example is the Ma/My mouse whose resistance is genetically dependent on the presence of genes encoding an activation receptor Ly49P, and $\mathrm{H}-2 \mathrm{D}^{\mathrm{k}}$ [61]. Epistatic interactions of these genes (or their gene products) confer resistance to MCMV. The Ly49P dependent activation of NK-cells is blocked by an antibody to $\mathrm{H}$ $2 \mathrm{D}^{\mathrm{k}}[61,62]$. In addition to $\mathrm{H}-2 \mathrm{D}^{\mathrm{k}}$ and Ly49P, the viral resistance of $\mathrm{Ma} / \mathrm{My}$ also requires $\mathrm{m04}$, a gene encoding gp34, a glycoprotein that escorts MHC-I to the surface and that inhibits recognition by $\mathrm{CD}^{+}$CTL. A $\Delta \mathrm{m} 04$ mutant of MCMV abrogates the resistance of Ma/My mice [30, 62, 63]. The mechanism by which these three gene products, Ly49P and $\mathrm{H}-2 \mathrm{D}^{\mathrm{k}}$ of the host, and m04 of MCMV, cooperatively generate viral resistance remains unclear.

\section{Biochemistry, Structure, and Evolution of Viral MHC-I-Like Molecules}

3.1. Interaction of MHC-I-Like MCMV Molecules and NK Receptors. Studies of the function of the MHC-I-like genes of the CMVs have largely relied on experiments with mutant viruses with engineered deletions of the relevant genes, on detection of cell surface expression of host proteins following infection or transfection, or on immunoprecipitation (pulldown) experiments using specific antibodies. Although such experiments support the conclusions that some of these viral MHC-I-like molecules either downregulate or impair the recognition of particular ligands, they fail to explain the precise molecular mechanism(s) involved in such regulatory effects $[39,44,50]$. To this end, several laboratories have directed efforts to engineer recombinant forms of the viral MHC-I-like proteins and their ligands and to measure these interactions in well-defined in vitro systems. Specifically, the interactions of MCMV m152 [46] and m157 [64, 65] and of HCMV UL18 [65] have been examined in this way.
The engineering, expression, and purification of soluble forms of the extracellular domains of 152 and RAE- $1 \beta,-1 \gamma$ (expressed in $\mathrm{BALB} / \mathrm{c})$, and RAE- $1 \delta(\mathrm{C} 57 \mathrm{BL} / 6)$ generated the reagents for size exclusion binding assays, analytical ultracentrifugation (AUC), and isothermal titration calorimetry (ITC), based on the hypothesis that the ectodomains m152 and RAE-1 isoforms interact directly. Recombinant $\mathrm{m} 152$, prepared in insect cells, interacted well with RAE-1 molecules refolded from $E$. coli inclusion bodies. Affinities for the interactions were measured by AUC with $\mathrm{K}_{d} \mathrm{~s}$ of RAE- $1 \gamma(1 \mu \mathrm{M})>$ RAE- $\beta(3 \mu \mathrm{M})>\operatorname{RAE}-1 \delta(30 \mu \mathrm{M})$ [46], which may be compared with the $\mathrm{K}_{\mathrm{d}}$ of the interaction of murine NKG2D with several RAE-1 isoforms (340-730 nM) [66]. The hierarchy of affinities of the different isoforms paralleled the effectiveness in the downregulation of RAE-1 by $\mathrm{m} 152$. In addition, these studies confirmed the predicted $1: 1$ stoichiometry of the m152: RAE-1 interaction.

The interaction between $\mathrm{m} 157$ and Ly49 NK receptors was first detected using m157-fusion proteins [56], or using an Ly49H-reporter cell and an m157 transfectant [67]. In experiments employing recombinant $\mathrm{m} 157, \mathrm{Ly} 49 \mathrm{H}$, and Ly49I and surface plasmon resonance (SPR) as well as ITC, the affinity of Ly49I for m157 was determined to have a $K_{d}$ of $0.2 \mu \mathrm{M}$ with a $1: 1$ stoichiometry, a stronger affinity than Ly49's interaction with standard MHC-I ligands $(1-80 \mu \mathrm{M})$ $[64,68,69]$.

UL18, an HCMV molecule that interacts with LIR1 (also known as ILT2 or CD85j), an inhibitory receptor expressed widely on monocytes, DCs, B cells, and some T cells and NKcells, has also been studied quantitatively by SPR methods. The interaction of LIR1 with UL18 $\left(\mathrm{K}_{\mathrm{d}} \sim 10^{-2} \mu \mathrm{M}\right)$ is $>1000$-fold stronger than that of LIR1 with classical MHCI [65]. It is interesting to note that the physical interaction between UL18 and the human NK-cell activating receptor, NKG2C/CD94, has been estimated to have a $\mathrm{K}_{\mathrm{d}}$ of about 10 to $100 \mu \mathrm{M}[70]$.

The quantitative measure of direct binding interactions between viral MHC-I like proteins and their ligands reflects the strength with which these evasins can compete with host protective or inhibitory mechanisms. Knowledge of the structural details of these interactions contributes to our understanding of the evolution and molecular mechanism of such viral MHC-I mimics.

\subsection{Structural Characteristics of CMV MHC-I-Like Molecules}

3.2.1. Amino Acid Sequence Similarities. The first CMV gene identified as an MHC-I homolog was H301 (now known as UL18) of HCMV, which was shown to encode a protein with $20 \%$ similarity to classical MHC-I proteins [71]. Subsequently, with the complete DNA sequence determination of the MCMV genome and bioinformatic analysis of its ORFs [23], m144 was shown to have amino acid sequence similarity to classical MHC-I proteins. Reexamination of ORFs of MCMV using more recently developed computational tools suggested the existence of other genes that encode MHCI-like molecules [72]. Simple alignment of classical MHC-I molecules from human and mouse reveals obvious sequence 
similarity over 267 amino acid residues of the extracellular domain with scores of $81 \%$ similarity and $71 \%$ identity (see Figure 2(a)). When UL18 and m144 are included in the sequence alignment, similarities, particularly in the conservation of cysteine residues, are still evident, although UL1 8 is only $24 \%$ identical with HLA-A2, and m144 is about $19 \%$ identical to H-2D ${ }^{d}$ (Figure 2(b)). However, efforts to align all the members of the m145 family from MCMV reveal profound differences in sequence and considerable problems in selecting appropriate computational parameters for the best alignment (Figure 2(c)). Sequence identity scores for the m145 family as compared with the classical MHC-I molecule $\mathrm{H}-2 \mathrm{D}^{\mathrm{d}}$ range from 6.2 (for $\mathrm{m} 151$ ) to $24.4 \%$ (for $\mathrm{m} 144$ ).

These rather marginal sequence similarities and the inherent ambiguities in evaluating the alignments of cysteine residues demand a more objective three-dimensional structural comparison.

3.2.2. Three-Dimensional Structures of Viral Evasins. The structures of three members of the m145 family (m144 [73], $\mathrm{m} 153$ [74], and $\mathrm{m} 157$ [64]) have been solved, as well as those of the HCMV UL18 $[75,76]$. In addition, a putative evasin of the tanapox virus $2 \mathrm{~L}$, which, remarkably, is also an MHCI-like molecule [77], has been examined in structural detail. Furthermore, structures of several other HCMV molecules, US2 and UL16, that function as immunoevasins, but are structurally related to the immunoglobulin superfamily and not related to the MHC-I family, have also been determined $[78,79]$.

Early studies of m144 suggested that it inhibited the recognition of virus-infected cells by NK-cells in vivo [80], and that $\mathrm{m} 144$ expression in tumor cells conferred resistance to NK-cell killing [81]. However, these results are controversial and there remains no consensus as to the function of the m144 glycoprotein.

Our lab has examined the expression and structure of m144 [73](PDB [82] code 1U58) (see Figure 3, Table 1). Biochemical analysis [83] of m144 revealed the lack of copurifying bound peptides, a result confirmed by transfection studies [73] that revealed the lack of a requirement for bound peptide for cell surface expression. The X-ray structure [73] shows a typical MHC-I fold consisting of $\alpha 1$ and $\alpha 2$ helices supported by a floor of antiparallel $\beta$ strands and connected via a loop to an immunoglobulin-like $\alpha 3$ domain. Although $\mathrm{m} 144$ cocrystalized with $\beta 2$-microglobulin $(\beta 2 \mathrm{~m})$, located in a canonical position beneath the $\beta$ strand floor, expression studies $[42,84]$ showed that there is no absolute $\beta 2 \mathrm{~m}$ requirement for folding and cell surface display. The $\alpha 1 \alpha 2$ domain unit is stabilized by two disulfide bonds: one that is similar in orientation to that found in classical MHC-I molecules (joining the $\beta 5$ strand to the $\alpha 2$ helix) and another unique one that links the $\alpha 1$ helix to $\beta 4$. The disulfide in the immunoglobulin-like $\alpha 3$ domain is conserved. The structure reveals truncated $\alpha 1$ and $\alpha 2$ helices, a narrowed groove, and a modified $\beta 2 \mathrm{~m}$ interface. An unstructured stretch of 13 amino acids not seen in the electron density map may be indicative of a flexible part of the molecule stabilized by a molecular partner [73].
The structure of $\mathrm{m} 153$ another member of the m145 family, with unknown function, has also been determined [74] (see Figure 3, Table 1). It was expressed and crystallized in the absence of $\beta 2 \mathrm{~m}$, which is not required for its cell surface expression. m153 is a noncovalently associated homodimer, not only in its crystal form but also as a purified protein and as expressed at the cell surface. $\mathrm{m} 153$ dimerizes in a head-to-tail fashion. Its aminoterminus is somewhat longer than that of classical MHC-I molecules and is tethered to its extended $\mathrm{H} 2 \mathrm{~b}$ helix via a disulfide bond. Another novel disulfide bond closes the loop connecting two $\beta$ strands, and a third disulfide, similarly positioned to that of classical MHC-I, is in the $\alpha 3$ domain. Like m144, it has a narrow potential binding groove, not apparently large enough to engage a peptide ligand. The tight juxtaposition of the $\alpha 1$ and $\alpha 2$ helices exposes a significant portion of the $\beta$ sheet floor. A coiled region separates the amino from the carboxylterminal parts of the $\alpha 2$ helix. Although the function of m153 remains as a conundrum, reporter cells constructed with the m153 extracellular domains indicate that some subsets of murine lymphoid cells ligate $\mathrm{m} 153$ and activate the reporter through this interaction [84]. Sequence alignment of m153 protein from different MCMV isolates identifies a conserved motif suggestive of an unchanging specific function [74, 87]. Although a definitive function for $\mathrm{m} 153$ has yet to be identified, m153 may play an important role in the viral life cycle as it is expressed early in infection and accumulates at the cell surface [84].

$\mathrm{m} 157$, a $37 \mathrm{kD}$ surface GPI-linked glycoprotein that is not required for viral replication in vitro, is the only known CMV-encoded cell surface molecule that can engage both NK activating (Ly49H) and inhibitory receptors (Ly49I) $[56,72]$. The structure of $\mathrm{m} 157$ [64] showcases a recognizable MHC-I fold with neither peptide binding groove nor $\beta 2 \mathrm{~m}$ association and a compactness enhanced by extensive intramolecular interactions. m157, like m153, has an extended aminoterminus, but for $\mathrm{m} 157$ this is a unique helical region, designated $\alpha 0$ (see Figure 3, Table 1). As with $\mathrm{m} 144$ and $\mathrm{m} 153$, the $\alpha 1$ juxtaposition to $\alpha 2$ precludes binding to a peptide antigen. Two intrachain disulfide bonds stabilize the $\alpha 1 \alpha 2$ domain, and the $\alpha 3$ domain has a disulfide as well. $\alpha 2$ is joined to $\alpha 3$ by an extended H2b helix, similar in conformation to that of m153. Mutagenesis and binding analysis suggest that $\mathrm{m} 157$ engages its Ly49H or Ly49I ligands through a surface distinct from that by which the homologous Ly49A binds to its $\mathrm{H}-2 \mathrm{D}^{\mathrm{d}}$ ligand.

The HCMV UL18 is closer in structure to classical MHCI molecules and to m144 than it is to m153 or m157 despite the fact that it is only about $25 \%$ identical in sequence to MHC-I. UL18 requires peptide and $\beta 2 \mathrm{~m}$ for proper folding [88], and binds the host inhibitory receptor LIR-1 with high affinity [75]. The $\alpha 1 \alpha 2$ domain preserves the highly conserved disulfide of MHC-I molecules, and also has a canonical disulfide bridge in the $\alpha 3$ domain. In addition, it links two adjacent $\beta$ strands of $\alpha 3$ with another disulfide (see Figure 3, Table 1). Both $\alpha 3$ domain disulfides are necessary for proper association with the LIR-1 ligand $[89,90]$.

The three-dimensional structure of the $2 \mathrm{~L}$ protein, another MHC-I homologue [85] of the human tanapox 


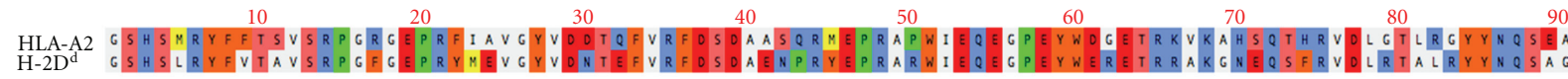

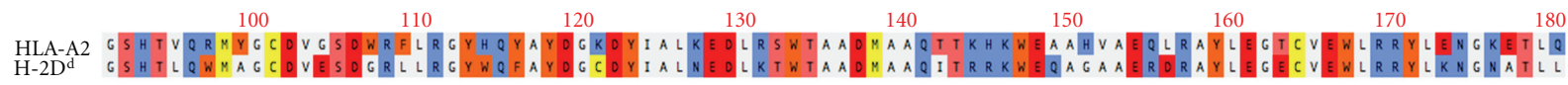

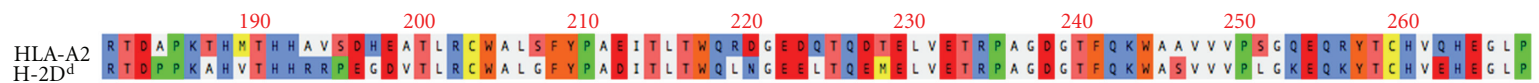

(a)

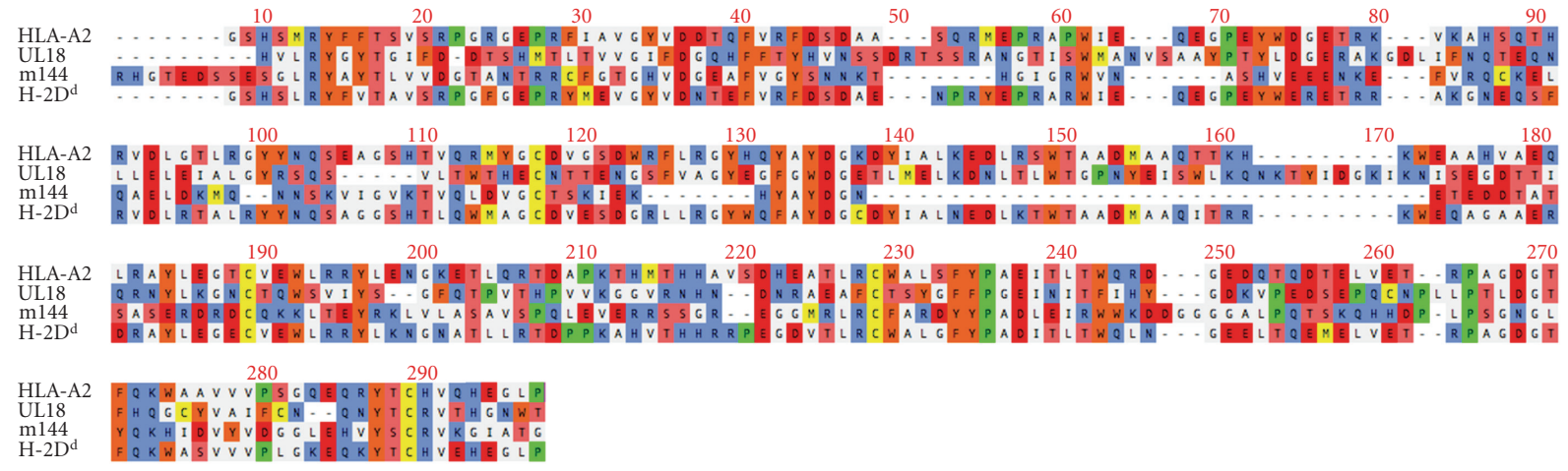

(b)

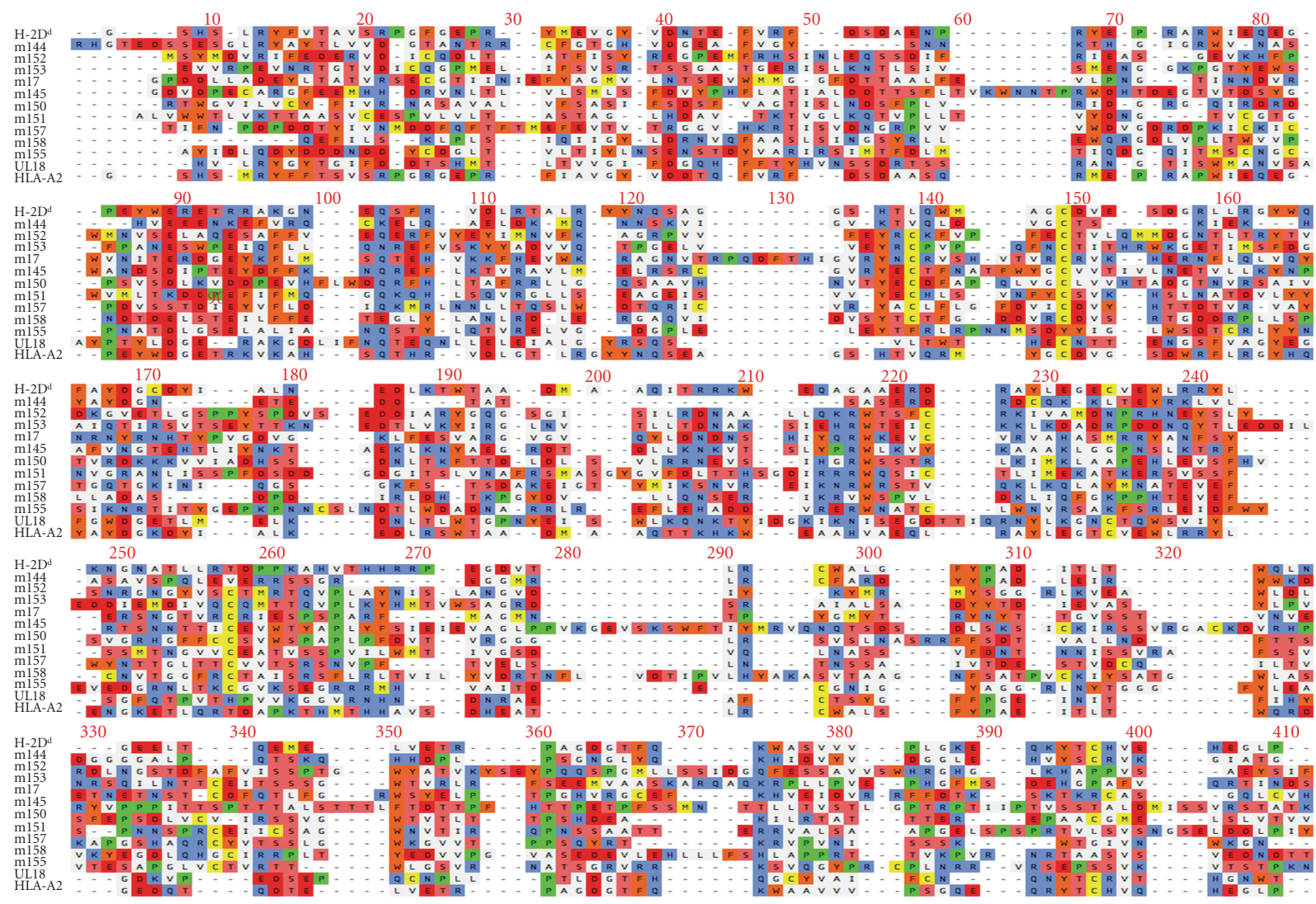

(c)

Figure 2: Amino acid sequence alignments of the extracellular domains of classical MHC-I molecules from mouse $\left(\mathrm{H}-2 \mathrm{D}^{\mathrm{d}}\right)$ and human (HLA-A2) with MHC-I-like viral immunoevasins were generated using ClustalW module of MacVector 10.6.6. H-2D ${ }^{\mathrm{d}}$ and HLA-A2 share significant similarity at $81.7 \%$ (a). UL18 and m144 show detectable sequence similarity (21-40\%) with HLA-A2 and H-2D ${ }^{\mathrm{d}}$. Conserved cysteine residues are in yellow (b). The alignment of m145 family members and other MHC-I-like immunoevasins shows 6-40\% sequence similarity to the canonical MHC-I molecules (c). 
TAble 1: (a) Subunit composition of MHC-I and MHC-I-like viral molecules. (b) Structural differences among MHC-I and MHC-I-like viral molecules.

(a)

\begin{tabular}{llc}
\hline Molecule & $\beta 2 \mathrm{~m}$ & Bound peptide ligand \\
\hline Classical MHC-I (e.g., HLA-A2, H-2D & yes \\
Viral MHC-I-like molecule & yes & yes \\
UL18 & & yes \\
m144 & yes & no \\
m153 & no & no \\
m157 & no & no \\
L & no & no \\
\hline
\end{tabular}

(b)

\begin{tabular}{|c|c|c|c|c|c|c|c|}
\hline \multirow{2}{*}{ Molecule } & \multirow{2}{*}{$\begin{array}{l}\text { Peptide } \\
\text { binding } \\
\text { groove }\end{array}$} & \multirow{2}{*}{$\begin{array}{l}\text { N-terminal } \\
\text { extension }\end{array}$} & \multirow{2}{*}{ H2b helix } & \multicolumn{2}{|c|}{ Canonical -S-S- } & \multicolumn{2}{|c|}{ Non-canonical -S-S- } \\
\hline & & & & $\begin{array}{l}\alpha 1 \alpha 2 \text { domain } \\
\beta 5 \rightarrow \alpha 2\end{array}$ & $\begin{array}{l}\alpha 3 \text { domain } \\
\beta 2 \rightarrow \beta 6\end{array}$ & $\alpha 1 \alpha 2$ domain & $\alpha 3$ domain \\
\hline $\begin{array}{l}\text { Classical MHC-I } \\
\text { (e.g., HLA-A2, H-2D }{ }^{\text {d }} \text { ) }\end{array}$ & yes & no & short & yes & yes & no & no \\
\hline \multicolumn{8}{|l|}{ Viral MHC-I-like } \\
\hline UL18 & yes & no & short & yes & yes & no & $\beta 4 \rightarrow \beta 5$ \\
\hline $\mathrm{m} 144$ & no & no & short & yes & yes & $\beta 2 \rightarrow \alpha 1$ & no \\
\hline $\mathrm{m} 153$ & no & Strand, coil & long & no & yes & $\beta 4 \rightarrow$ loop 5 & $\mathrm{~N}$-term $\rightarrow \mathrm{H} 2 \mathrm{~b}$ \\
\hline $\mathrm{m} 157$ & no & $\alpha 0$ helix & long & no & yes & Loop 4 & $\beta 5 \rightarrow \beta 6$ \\
\hline $2 \mathrm{~L}$ & no & no & no & no & yes & no & C-term loop \\
\hline
\end{tabular}

virus, has also been determined [77]. Tanapox is a Yatapoxvirus, only distantly related to the Herpesviridae to which the CMVs belong. The $2 \mathrm{~L}$ molecule binds TNF- $\alpha$, in a highaffinity interaction that accounts for inhibition of immune function such as TNF-mediated cellular cytotoxicity. The $\mathrm{X}$-ray structure of the complex of $2 \mathrm{~L}$ with TNF- $\alpha$ reveals a molecule that lacks the typical MHC-I peptide binding groove. The amino-terminal parts of the $\alpha 1$ and $\alpha 2$ helices are displaced toward the opposite helix, closing the groove. One disulfide bond links the $\beta$ strand floor to the $\alpha 2$ helix like classical MHC-I molecules, while two others stabilize the $\alpha 3$ domain (see Figure 3, Table 1). The site of interaction between $2 \mathrm{~L}$ and TNF- $\alpha$ is a large and complementary interface that includes residue of both the $\alpha 2$ and $\alpha 3$ domains of $2 \mathrm{~L}$. Thus, $2 \mathrm{~L}$ preserves the basic MHC-I fold, lacks peptide or $\beta 2 \mathrm{~m}$, and interacts with the trimeric TNF- $\alpha$ in a novel way.

\section{Viral MHC-I-Like Gene Evolution}

CMVs and their respective hosts have coevolved, and the origin of the most recent common root for the three families of the Herpesviridae (i.e., the $\alpha, \beta$, and $\gamma$-Herpesvirinae) has been estimated to have occurred about 400 million years ago (Ma) [91]. Under the selection of the host immune response, the virus has developed biological solutions for its continued survival. Although a conserved core of genes is observed for the herpesvirus genomes [92], there exist a number of genes, homologous to those of the host [93] which appear to have originated in the host and to have been acquired by lateral (horizontal) transmission. There are many viral genes that on initial evaluation exhibit a very low level of nucleic acid sequence similarity to host genes, but whose ORFs likely encode proteins similar to those of the host. Even more distantly related viral genes are observed, some of which encode proteins that have little or no amino acid sequence similarity to proteins from their hosts, but whose relationship to host proteins may be deduced through various secondary structure threading programs such as 3DPSSM [94, 95] or phyre [96, 97]. The viral MHC-I-like proteins fall into this latter category, revealing amino acid sequence identity as low as $6 \%$. The evolutionary origin of many of these proteins and their encoding genes, although they seem to have been derived from the host, remains unclear, and efforts to understand their origin rely not only on nucleic acid and protein sequence comparison, but also on a knowledge of the function and structure of the expressed proteins. With the goal of understanding the function and evolution of these genes, several laboratories have determined the three-dimensional structure of representative viral MHC-I-like molecules, and the comparisons that we have summarized above confirm that m144, UL18, $\mathrm{m} 153, \mathrm{~m} 157$ of the CMV family, and 2L of the more distantly related tanapox virus all clearly have structural features in common (see Table 1). The structural similarity of each of these proteins to other MHC-I, for example, H-2D ${ }^{\mathrm{d}}$ [86] and MHC-I-like molecules is established not only by an intuitive sense based on the similarity of the location and orientation of secondary structural elements, it is strongly 

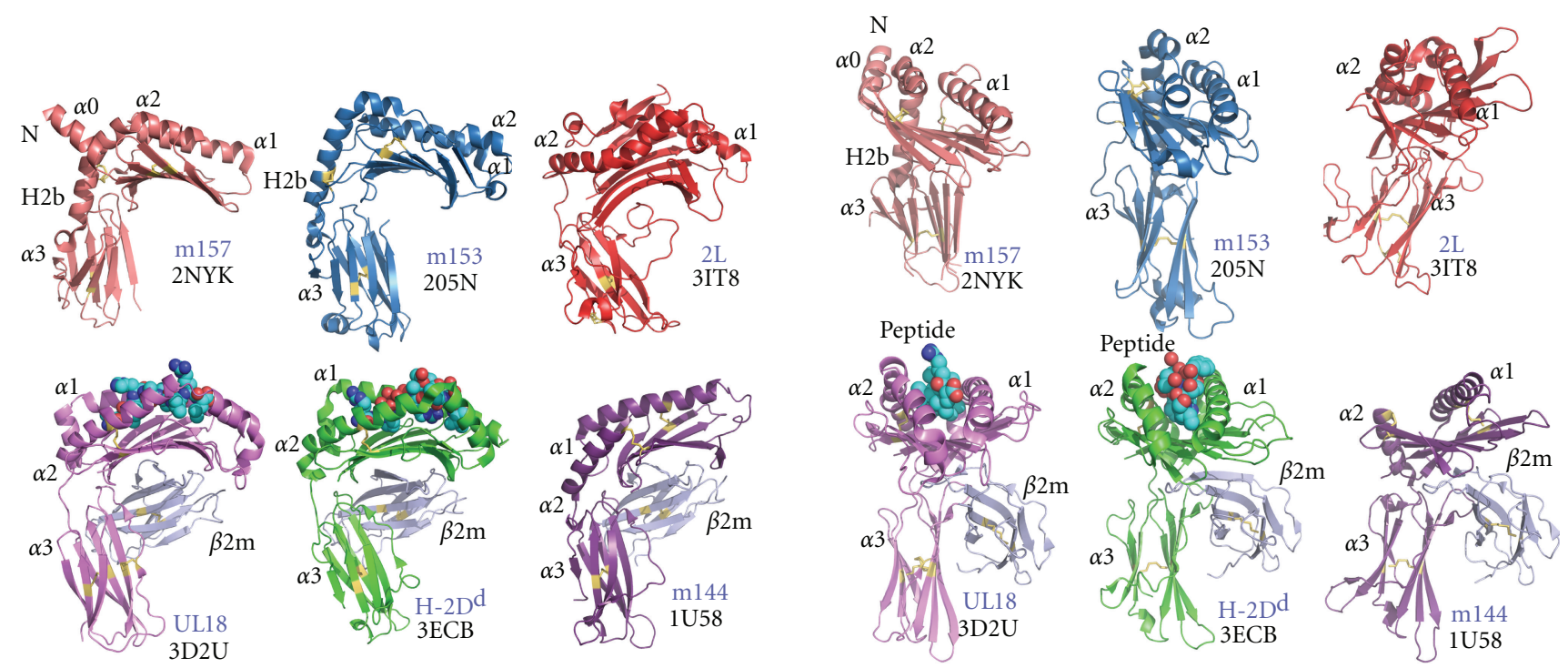

(a)

(b)

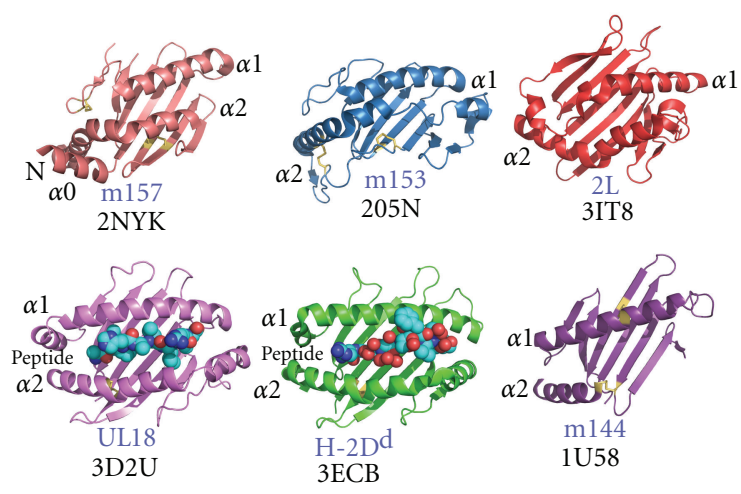

(c)

Figure 3: X-ray structures of m157 (2NYK) [64], m153 (205N) [74, 84], m144 (IU58), HCMV UL18 (3D2U) [75], Tanapox 2L protein (3IT8) [85], and H-2 $\mathrm{D}^{\mathrm{d}}$ (3ECB) [86] reveal both shared and unique features. The disulfide bonds are in yellow. The $\alpha 1, \alpha 2$ and $\mathrm{H} 2 \mathrm{~b}$ helices and $\alpha 3$ domain are labeled. Ribbon diagrams of the structures in (a), rotated $90^{\circ}$ to the right in (b), reveal differences in $\beta 2 \mathrm{~m}$ and peptide binding $(\mathrm{a}, \mathrm{b})$. The view from the top shows differences in the peptide binding pocket (c). Illustrations were prepared from the superposed structures of the molecules using PyMOL http://www.pymol.org/.

confirmed by quantitative computational superpositions of the crystallographic structures calculated with programs such as Dali [98], Pymol [99], and lsqkab [100].

Thus, arguments for the relationship of these representative proteins and their encoding genes can be made forcefully. In addition, particularly among the rodent members of the 145 family, the amino acid sequence similarities support the notion of a common ancestor. The most difficult problem is whether or not a single evolutionary event, in which a gene encoding a vertebrate MHC-I-like molecule was captured by a single large DNA virus as much as $400 \mathrm{Ma}$, has given rise to the genes that encode MHC-I-like molecules identifiable in a number of viral species, or whether several independent capture events have occurred for different viruses. The observation that the HCMV protein UL18 and the MCMV protein m144 appear to be closer in structure to classical MHC-I molecules and that the other MCMV proteins, m153 and m157, are more distantly related, favors a single ancient origin. Whether such a hypothesis can withstand the identification, amino acid sequence, and structural analysis of previously unidentified CMV and other viral immunoevasins related to classical MHC-I molecules remains to be determined.

\section{Acknowledgment}

This work was supported by the Intramural Research Program of the Laboratory of Immunology, National Institute of Allergy and Infectious Diseases, National Institutes of Health, Bethesda, MD.

\section{References}

[1] M. J. Reddehase, "Antigens and immunoevasins: opponents in cytomegalovirus immune surveillance," Nature Reviews Immunology, vol. 2, no. 11, pp. 831-844, 2002. 
[2] D. J. McGeoch, S. Cook, A. Dolan, F. E. Jamieson, and E. A. R. Telford, "Molecular phylogeny and evolutionary timescale for the family of mammalian herpesviruses," Journal of Molecular Biology, vol. 247, no. 3, pp. 443-458, 1995.

[3] H. Hengel, U. Reusch, A. Gutermann et al., "Cytomegaloviral control of MHC class I function in the mouse," Immunological Reviews, vol. 168, pp. 167-176, 1999.

[4] M. M. Crumpler, K. Y. Choi, M. A. McVoy, and M. R. Schleiss, "A live guinea pig cytomegalovirus vaccine deleted of three putative immune evasion genes is highly attenuated but remains immunogenic in a vaccine/challenge model of congenital cytomegalovirus infection," Vaccine, vol. 27, no. 31, pp. 4209-4218, 2009.

[5] W. T. London, A. J. Martinez, and S. A. Houff, "Experimental congenital disease with simian cytomegalovirus in rhesus monkeys," Teratology, vol. 33, no. 3, pp. 323-331, 1986.

[6] G. B. Baskin, "Disseminated cytomegalovirus infection in immunodeficient rhesus monkeys," American Journal of Pathology, vol. 129, no. 2, pp. 345-352, 1987.

[7] V. DeFilippis and K. Früh, "Rhesus cytomegalovirus particles prevent activation of interferon regulatory factor 3," Journal of Virology, vol. 79, no. 10, pp. 6419-6431, 2005.

[8] C. Powers and K. Früh, "Rhesus CMV: an emerging animal model for human CMV," Medical Microbiology and Immunology, vol. 197, no. 2, pp. 109-115, 2008.

[9] K. M. Lockridge, G. Sequar, S. S. Zhou, Y. Yue, C. P. Mandell, and P. A. Barry, "Pathogenesis of experimental rhesus cytomegalovirus infection," Journal of Virology, vol. 73, no. 11, pp. 9576-9583, 1999.

[10] M. Miller-Kittrell, J. Sai, M. Penfold, A. Richmond, and T. E. Sparer, "Functional characterization of chimpanzee cytomegalovirus chemokine, vCXCL-1(CCMV)," Virology, vol. 364, no. 2, pp. 454-465, 2007.

[11] A. J. Davison, A. Dolan, P. Akter et al., "The human cytomegalovirus genome revisited: comparison with the chimpanzee cytomegalovirus genome," Journal of General Virology, vol. 84, no. 1, pp. 17-28, 2003.

[12] V. Misra and J. B. Hudson, "Minor base sequence differences between the genomes of two strains of murine cytomegalovirus differing in virulence," Archives of Virology, vol. 64 , no. 1 , pp. $1-8,1980$.

[13] M. Pyzik, A. Kielczewska, and S. M. Vidal, "NK cell receptors and their MHC class I ligands in host response to cytomegalovirus: insights from the mouse genome," Seminars in Immunology, vol. 20, no. 6, pp. 331-342, 2008.

[14] M. G. Smith, "Propagation of salivary gland virus of the mouse in tissue cultures," Proceedings of the Society for Experimental Biology and Medicine, vol. 86, no. 3, pp. 435440, 1954.

[15] A. Krmpotic, I. Bubic, B. Polic, P. Lucin, and S. Jonjic, "Pathogenesis of murine cytomegalovirus infection," Microbes and Infection, vol. 5, no. 13, pp. 1263-1277, 2003.

[16] C. Powers, V. DeFilippis, D. Malouli, and K. Früh, "Cytomegalovirus immune evasion," Current Topics in Microbiology and Immunology, vol. 325, pp. 333-359, 2008.

[17] M. J. Cannon, D. S. Schmid, and T. B. Hyde, "Review of cytomegalovirus seroprevalence and demographic characteristics associated with infection," Reviews in Medical Virology, vol. 20, no. 4, pp. 202-213, 2010.

[18] M. R. Schleiss, "Nonprimate models of congenital cytomegalovirus (CMV) infection: gaining insight into pathogenesis and prevention of disease in newborns," ILAR Journal, vol. 47, no. 1, pp. 65-72, 2006.
[19] J. S. Orange, M. S. Fassett, L. A. Koopman, J. E. Boyson, and J. L. Strominger, "Viral evasion of natural killer cells," Nature Immunology, vol. 3, no. 11, pp. 1006-1012, 2002.

[20] M. J. Reddehase, W. Mutter, K. Münch, H. J. Bühring, and U. H. Koszinowski, "CD8-positive T lymphocytes specific for murine cytomegalovirus immediate-early antigens mediate protective immunity," Journal of Virology, vol. 61, no. 10, pp. 3102-3108, 1987.

[21] X. He, H. Yoshida, Y. Minamishima, and K. Nomoto, "Analysis of the role of CD4+ T-cells during murine cytomegalovirus infection in different strains of mice," Virus Research, vol. 36, no. 2-3, pp. 233-245, 1995.

[22] E. Wiertz, A. Hill, D. Tortorella, and H. Ploegh, "Cytomegaloviruses use multiple mechanisms to elude the host immune response," Immunology Letters, vol. 57, no. 1-3, pp. 213-216, 1997.

[23] W. D. Rawlinson, H. E. Farrell, and B. G. Barrell, "Analysis of the complete DNA sequence of murine cytomegalovirus," Journal of Virology, vol. 70, no. 12, pp. 8833-8849, 1996.

[24] L. Brocchieri, T. N. Kledal, S. Karlin, and E. S. Mocarski, "Predicting coding potential from genome sequence: application to betaherpesviruses infecting rats and mice," Journal of Virology, vol. 79, no. 12, pp. 7570-7596, 2005.

[25] S. F. Altschul, T. L. Madden, A. A. Schäffer et al., "Gapped BLAST and PSI-BLAST: a new generation of protein database search programs," Nucleic Acids Research, vol. 25, no. 17, pp. 3389-3402, 1997.

[26] D. G. Kavanagh, U. H. Koszinowski, and A. B. Hill, "The murine cytomegalovirus immune evasion protein m4/gp34 forms biochemically distinct complexes with class I MHC at the cell surface and in a pre-golgi compartment," Journal of Immunology, vol. 167, no. 7, pp. 3894-3902, 2001.

[27] M. F. Kleijnen, J. B. Huppa, P. Lucin et al., "A mouse cytomegalovirus glycoprotein, gp34, forms a complex with folded class I MHC molecules in the ER which is not retained but is transported to the cell surface," The EMBO Journal, vol. 16, no. 4, pp. 685-694, 1997.

[28] K. Natarajan, N. Dimasi, J. Wang, D. H. Margulies, and R. A. Mariuzza, "MHC class I recognition by Ly49 natural killer cell receptors," Molecular Immunology, vol. 38, no. 14, pp. 1023-1027, 2002.

[29] K. Natarajan, N. Dimasi, J. Wang, R. A. Mariuzza, and D. H. Margulies, "Structure and function of natural killer cell receptors: multiple molecular solutions to self, nonself discrimination," Annual Review of Immunology, vol. 20, pp. 853-885, 2002.

[30] J. C. Sun and L. L. Lanier, "The natural selection of herpesviruses and virus-specific NK cell receptors," Viruses, vol. 1, no. 3, p. 362, 2009.

[31] S. Bahram, "MIC genes: from genetics to biology," Advances in Immunology, vol. 76, pp. 1-60, 2000.

[32] D. Cosman, J. Müllberg, C. L. Sutherland et al., "ULBPs, novel MHC class I-related molecules, bind to CMV glycoprotein UL16 and stimulate NK cytotoxicity through the NKG2D receptor," Immunity, vol. 14, no. 2, pp. 123-133, 2001.

[33] C. Dunn, N. J. Chalupny, C. L. Sutherland et al., "Human cytomegalovirus glycoprotein UL16 causes intracellular sequestration of NKG2D ligands, protecting against natural killer cell cytotoxicity," Journal of Experimental Medicine, vol. 197, no. 11, pp. 1427-1439, 2003.

[34] C. L. Sutherland, N. Jan Chalupny, and D. Cosman, "The UL16-binding proteins, a novel family of MHC class I-related ligands for NKG2D, activate natural killer cell functions," Immunological Reviews, vol. 181, pp. 185-192, 2001. 
[35] A. B. H. Bakker, R. M. Hoek, A. Cerwenka et al., "DAP12deficient mice fail to develop autoimmunity due to impaired antigen priming," Immunity, vol. 13, no. 3, pp. 345-353, 2000.

[36] L. N. Carayannopoulos, O. V. Naidenko, D. H. Fremont, and W. M. Yokoyama, "Cutting edge: murine UL16-binding protein-like transcript 1: a newly described transcript encoding a high-affinity ligand for murine NKG2D," Journal of Immunology, vol. 169, no. 8, pp. 4079-4083, 2002.

[37] L. N. Carayannopoulos, O. V. Naidenko, J. Kinder, E. L. Ho, D. H. Fremont, and W. M. Yokoyama, "Ligands for murine NKG2D display heterogeneous binding behavior," European Journal of Immunology, vol. 32, no. 3, pp. 597-605, 2002.

[38] A. Cerwenka, A. B. H. Bakker, T. McClanahan et al., "Retinoic acid early inducible genes define a ligand family for the activating NKG2D receptor in mice," Immunity, vol. 12, no. 6, pp. 721-727, 2000.

[39] A. Diefenbach, A. M. Jamieson, S. D. Liu, N. Shastri, and D. H. Raulet, "Ligands for the murine NKG2D receptor: expression by tumor cells and activation of NK cells and macrophages," Nature Immunology, vol. 1, no. 2, pp. 119126, 2000.

[40] L. L. Lanier, "DAP10- and DAP12-associated receptors in innate immunity," Immunological Reviews, vol. 227, no. 1, pp. 150-160, 2009.

[41] S. Gilfillan, E. M. Ho, M. Cella, W. M. Yokohama, and M. Colonna, "NKG2D recriuts two distinct adapters to trigger NK cell activation and costimulation," Nature Immunology, vol. 3, no. 12, pp. 1150-1155, 2002.

[42] A. Diefenbach, E. Tomasello, M. Lucas et al., "Selective associations with signaling proteins determine stimulatory versus costimulatory activity of NKG2D," Nature Immunology, vol. 3, no. 12, pp. 1142-1149, 2002.

[43] J. L. Upshaw, L. N. Arneson, R. A. Schoon, C. J. Dick, D. D. Billadeau, and P. J. Leibson, "NKG2D-mediated signaling requires a DAP10-bound Grb2-Vav1 intermediate and phosphatidylinositol-3-kinase in human natural killer cells," Nature Immunology, vol. 7, no. 5, pp. 524-532, 2006.

[44] M. Lodoen, K. Ogasawara, J. A. Hamerman et al., "NKG2D-mediated natural killer cell protection against cytomegalovirus is impaired by viral gp40 modulation of retinoic acid early inducible 1 gene molecules," Journal of Experimental Medicine, vol. 197, no. 10, pp. 1245-1253, 2003.

[45] A. Krmpotíc, D. H. Busch, I. Bubíc et al., "MCMV glycoprotein gp40 confers virus resistance to CD8 T cells and NK cells in vivo," Nature Immunology, vol. 3, no. 6, pp. 529-535, 2002.

[46] LI. Zhi, J. Mans, M. J. Paskow et al., "Direct interaction of the mouse cytomegalovirus $\mathrm{m} 152 / \mathrm{gp} 40$ immunoevasin with RAE-1 isoforms," Biochemistry, vol. 49, no. 11, pp. 2443 2453, 2010.

[47] A. Krmpotic, M. Hasan, A. Loewendorf et al., "NK cell activation through the NKG2D ligand MULT-1 is selectively prevented by the glycoprotein encoded by mouse cytomegalovirus gene m145," Journal of Experimental Medicine, vol. 201, no. 2, pp. 211-220, 2005.

[48] M. Hasan, A. Krmpotic, Z. Ruzsics et al., "Selective downregulation of the NKG2D ligand $\mathrm{H} 60$ by mouse cytomegalovirus m155 glycoprotein," Journal of Virology, vol. 79, no. 5, pp. 2920-2930, 2005.

[49] J. D. Mintern, E. J. Klemm, M. Wagner et al., "Viral interference with B7-1 costimulation: a new role for murine cytomegalovirus Fc receptor-1," Journal of Immunology, vol. 177, no. 12, pp. 8422-8431, 2006.
[50] J. Arapović, T. Lenac, R. Antulov et al., "Differential susceptibility of RAE-1 isoforms to mouse cytomegalovirus," Journal of Virology, vol. 83, no. 16, pp. 8198-8207, 2009.

[51] H. G. Ljunggren and K. Karre, "In search of the 'missing self': MHC molecules and NK cell recognition," Immunology Today, vol. 11, no. 7, pp. 237-244, 1990.

[52] K. Natarajan, L. F. Boyd, P. Schuck, W. M. Yokoyama, D. Eilat, and D. H. Margulies, "Interaction of the NK cell inhibitory receptor Ly49A with $\mathrm{H}-2 \mathrm{D}(\mathrm{d})$ : identification of a site distinct from the TCR site," Immunity, vol. 11, no. 5, pp. 591-601, 1999.

[53] J. Tormo, K. Natarajan, D. H. Margulles, and R. A. Mariuzza, "Crystal structure of a lectin-like natural killer cell receptor bound to its MHC class I ligand," Nature, vol. 402, no. 6762, pp. 623-631, 1999.

[54] W. Held and D. H. Raulet, "Ly49A transgenic mice provide evidence for a major histocompatibility complex-dependent education process in natural killer cell development," Journal of Experimental Medicine, vol. 185, no. 12, pp. 2079-2088, 1997.

[55] A. H. Jonsson, L. Yang, S. Kim, S. M. Taffner, and W. M. Yokoyama, "Effects of MHC class I alleles on licensing of Ly49A+ NK cells," Journal of Immunology, vol. 184, no. 7, pp. 3424-3432, 2010.

[56] H. Arase, E. S. Mocarski, A. E. Campbell, A. B. Hill, and L. L. Lanier, "Direct recognition of cytomegalovirus by activating and inhibitory NK cell receptors," Science, vol. 296, no. 5571, pp. 1323-1326, 2002.

[57] I. Bubić, M. Wagner, A. Krmpotić et al., "Gain of virulence caused by loss of a gene in murine cytomegalovirus," Journal of Virology, vol. 78, no. 14, pp. 7536-7544, 2004.

[58] J. R. Carlyle, A. Mesci, J. H. Fine et al., "Evolution of the Ly49 and Nkrp1 recognition systems," Seminars in Immunology, vol. 20, no. 6, pp. 321-330, 2008.

[59] V. Voigt, C. A. Forbes, J. N. Tonkin et al., "Murine cytomegalovirus m157 mutation and variation leads to immune evasion of natural killer cells," Proceedings of the National Academy of Sciences of the United States of America, vol. 100, no. 23, pp. 13483-13488, 2003.

[60] A. J. Corbett, J. D. Coudert, C. A. Forbes, and A. A. Scalzo, "Functional consequences of natural sequence variation of murine cytomegalovirus m157 for Ly49 receptor specificity and NK cell activation," Journal of Immunology, vol. 186, no. 3, pp. 1713-1722, 2011.

[61] M.-P. Desrosiers, A. Kielczewska, J.-C. Loredo-Osti et al., "Epistasis between mouse Klra and major histocompatibility complex class I loci is associated with a new mechanism of natural killer cell-mediated innate resistance to cytomegalovirus infection," Nature Genetics, vol. 37, no. 6, pp. 593-599, 2005.

[62] A. Kielczewska, M. Pyzik, T. Sun et al., "Ly49P recognition of cytomegalovirus-infected cells expressing H2-D and CMVencoded m04 correlates with the NK cell antiviral response," Journal of Experimental Medicine, vol. 206, no. 3, pp. 515523, 2009.

[63] L. L. Lanier, "Evolutionary struggles between NK cells and viruses," Nature Reviews Immunology, vol. 8, no. 4, pp. 259268, 2008.

[64] E. J. Adams, Z. S. Juo, R. T. Venook et al., "Structural elucidation of the m157 mouse cytomegalovirus ligand for Ly49 natural killer cell receptors," Proceedings of the National Academy of Sciences of the United States of America, vol. 104, no. 24, pp. 10128-10133, 2007. 
[65] T. L. Chapman, A. P. Heikema, and P. J. Bjorkman, "The inhibitory receptor LIR-1 uses a common binding interaction to recognize class I MHC molecules and the viral homolog UL18," Immunity, vol. 11, no. 5, pp. 603-613, 1999.

[66] C. A. O'Callaghan, A. Cerwenka, B. E. Willcox, L. L. Lanier, and P. J. Bjorkman, "Molecular competition for NKG2D: H60 and RAE1 compete unequally for NKG2D with dominance of H60," Immunity, vol. 15, no. 2, pp. 201-211, 2001.

[67] A. H. Davis, N. V. Guseva, B. L. Ball, and J. W. Heusel, "Characterization of murine cytomegalovirus ml57 from infected cells and identification of critical residues mediating recognition by the NK cell receptor Ly49H," Journal of Immunology, vol. 181, no. 1, pp. 265-275, 2008.

[68] J. Wang, M. C. Whitman, K. Natarajan, J. Tormo, R. A. Mariuzza, and D. H. Margulies, "Binding of the natural killer cell inhibitory receptor Ly49A to its major histocompatibility complex class I ligand: crucial contacts include both $\mathrm{H}$ $2 \mathrm{D}$ and $\beta$-microglobulin," Journal of Biological Chemistry, vol. 277, no. 2, pp. 1433-1442, 2002.

[69] J. Dam, R. Guan, K. Natarajan et al., "Variable MHC class I engagement by Ly49 natural killer cell receptors demonstrated by the crystal structure of Ly49C bound to $\mathrm{H}$ 2K," Nature Immunology, vol. 4, no. 12, pp. 1213-1222, 2003.

[70] B. K. Kaiser, J. C. Pizarro, J. Kerns, and R. K. Strong, "Structural basis for NKG2A/CD94 recognition of HLA-E," Proceedings of the National Academy of Sciences of the United States of America, vol. 105, no. 18, pp. 6696-6701, 2008.

[71] S. Beck and B. G. Barrell, "Human cytomegalovirus encodes a glycoprotein homologous to MHC class-I antigens," Nature, vol. 331, no. 6153, pp. 269-272, 1988.

[72] H. R. C. Smith, J. W. Heusel, I. K. Mehta et al., "Recognition of a virus-encoded ligand by a natural killer cell activation receptor," Proceedings of the National Academy of Sciences of the United States of America, vol. 99, no. 13, pp. 8826-8831, 2002.

[73] K. Natarajan, A. Hicks, J. Mans et al., "Crystal structure of the murine cytomegalovirus MHC-I homolog m144," Journal of Molecular Biology, vol. 358, no. 1, pp. 157-171, 2006.

[74] J. Mans, K. Natarajan, A. Balbo et al., "Cellular expression and crystal structure of the murine cytomegalovirus major histocompatibility complex class I-like glycoprotein, m153," Journal of Biological Chemistry, vol. 282, no. 48, pp. 3524735258, 2007.

[75] Z. Yang and P. J. Bjorkman, "Structure of UL18, a peptidebinding viral MHC mimic, bound to a host inhibitory receptor," Proceedings of the National Academy of Sciences of the United States of America, vol. 105, no. 29, pp. 1009510100, 2008.

[76] F. Yang, A. P. West, and P. J. Bjorkman, "Crystal structure of a

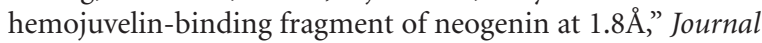
of Structural Biology, vol. 174, no. 1, pp. 239-244, 2011.

[77] Z. Yang, A. P. West, and P. J. Bjorkman, "Crystal structure of TNF $\alpha$ complexed with a poxvirus MHC-related TNF binding protein," Nature Structural and Molecular Biology, vol. 16, no. 11, pp. 1189-1191, 2009.

[78] B. E. Gewurz, R. Gaudet, D. Tortorella, E. W. Wang, H. L. Ploegh, and D. C. Wiley, "Antigen presentation subverted: structure of the human cytomegalovirus protein US2 bound to the class I molecule HLA-A2," Proceedings of the National Academy of Sciences of the United States of America, vol. 98, no. 12, pp. 6794-6799, 2001.
[79] S. Müller, G. Zocher, A. Steinle, and T. Stehle, "Structure of the HCMV UL16-MICB complex elucidates select binding of a viral immunoevasin to diverse NKG2D ligands," PLoS Pathogens, vol. 6, no. 1, Article ID e1000723, 2010.

[80] H. E. Farrell, H. Vally, D. M. Lynch et al., "Inhibition of natural killer cells by a cytomegalovirus MHC class I homologue in vivo," Nature, vol. 386, no. 6624, pp. 510-514, 1997.

[81] E. Cretney, M. A. Degli-Esposti, E. H. Densley, H. E. Farrell, N. J. Davis-Poynter, and M. J. Smyth, "m144, a murine cytomegalovirus (MCMV)-encoded major histocompatibility complex class I homologue, confers tumor resistance to natural killer cell-mediated rejection," Journal of Experimental Medicine, vol. 190, no. 3, pp. 435-443, 1999.

[82] J. Westbrook, Z. Feng, S. Jain et al., “The protein data bank: unifying the archive," Nucleic Acids Research, vol. 30, no. 1, pp. 245-248, 2002.

[83] T. L. Chapman and P. J. Bjorkman, "Characterization of a murine cytomegalovirus class I major histocompatibility complex (MHC) homolog: comparison to MHC molecules and to the human cytomegalovirus MHC homolog," Journal of Virology, vol. 72, no. 1, pp. 460-466, 1998.

[84] J. Mans, Characterization of mouse cytomegalovirus MHC-I homologs, Doctoral Dissertation, Faculty of Health Scuences, University of Witwatersrand, Johannesburg, South Africa, 2008.

[85] M. M. Rahman, D. Jeng, R. Singh, J. Coughlin, K. Essani, and G. McFadden, "Interaction of human TNF and $\beta 2$ microglobulin with Tanapox virus-encoded TNF inhibitor, TPV-2L," Virology, vol. 386, no. 2, pp. 462-468, 2009.

[86] R. Wang, K. Natarajan, and D. H. Margulies, "Structural basis of the CD $8 \alpha \beta / \mathrm{MHC}$ class I interaction: focused recognition orients CD8 $\beta$ to a T cell proximal position," Journal of Immunology, vol. 183, no. 4, pp. 2554-2564, 2009.

[87] J. Mans, L. I. Zhi, M. J. R. Revilleza et al., "Structure and function of murine cytomegalovirus MHC-I-like molecules: how the virus turned the host defense to its advantage," Immunologic Research, vol. 43, no. 1-3, pp. 264-279, 2009.

[88] M. L. Fahnestock, J. L. Johnson, R. M. Renny Feldman, J. M. Neveu, W. S. Lane, and P. J. Bjorkman, "The MHC class I homolog encoded by human cytomegalovirus binds endogenous peptides," Immunity, vol. 3, no. 5, pp. 583-590, 1995.

[89] C. S. Wagner, A. Rölle, D. Cosman, H. G. Ljunggren, K. D. Berndt, and A. Achour, "Structural elements underlying the high binding affinity of human cytomegalovirus UL18 to leukocyte immunoglobulin-like receptor-1," Journal of Molecular Biology, vol. 373, no. 3, pp. 695-705, 2007.

[90] M. Occhino, F. Ghiotto, S. Soro et al., "Dissecting the structural determinants of the interaction between the human cytomegalovirus UL18 protein and the CD85j immune receptor," Journal of Immunology, vol. 180, no. 2, pp. 957968, 2008.

[91] D. J. McGeoch, D. Gatherer, and A. Dolan, "On phylogenetic relationships among major lineages of the Gammaherpesvirinae," Journal of General Virology, vol. 86, no. 2, pp. 307-316, 2005.

[92] D. J. McGeoch, A. Dolan, and A. C. Ralph, "Toward a comprehensive phylogeny for mammalian and avian herpesviruses," Journal of Virology, vol. 74, no. 22, pp. 1040110406, 2000.

[93] M. Raftery, A. Muller, and G. Schonrich, "Herpesvirus homologues of cellular genes," Virus Genes, vol. 21, no. 1-2, pp. $65-75,2000$. 
[94] P. A. Bates, L. A. Kelley, R. M. MacCallum, and M. J. E. Sternberg, "Enhancement of protein modeling by human intervention in applying the automatic programs 3DJIGSAW and 3D-PSSM," Proteins: Structure, Function and Genetics, vol. 45, supplement 5, pp. 39-46, 2001.

[95] L. A. Kelley, R. M. MacCallum, and M. J. E. Sternberg, "Enhanced genome annotation using structural profiles in the program 3D-PSSM," Journal of Molecular Biology, vol. 299, no. 2, pp. 499-520, 2000.

[96] L. A. Kelley and M. J. Sternberg, "Protein structure prediction on the Web: a case study using the Phyre server," Nature Protocols, vol. 4, no. 3, pp. 363-371, 2009.

[97] R. M. Bennett-Lovsey, A. D. Herbert, M. J. E. Sternberg, and L. A. Kelley, "Exploring the extremes of sequence/structure space with ensemble fold recognition in the program Phyre," Proteins: Structure, Function and Genetics, vol. 70, no. 3, pp. 611-625, 2008.

[98] L. Holm and P. Rosenström, "Dali server: conservation mapping in 3D," Nucleic Acids Research, vol. 38, no. 2, pp. W545W549, 2010.

[99] "The PyMOL Molecular Graphics System," V.X.H., Schrödinger, LLC.

[100] N. Collaborative Computational Project, "The CCP4 suite: programs for protein crystallography," Acta Crystallographica, vol. D50, pp. 760-763, 1997. 


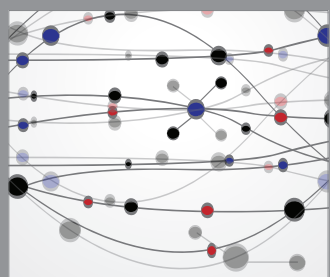

The Scientific World Journal
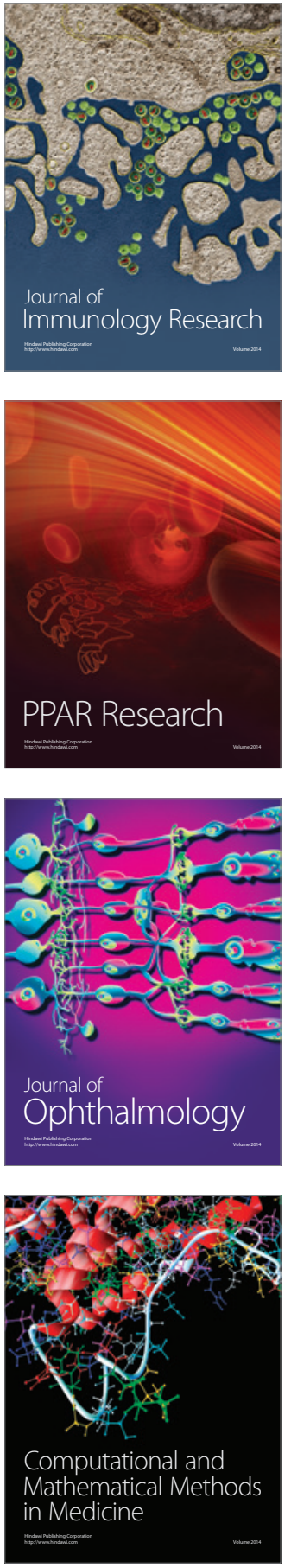

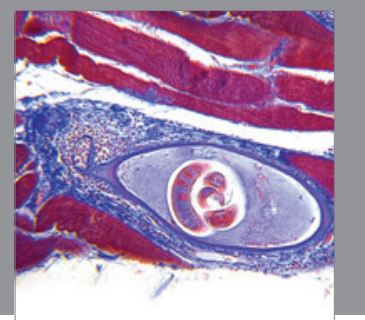

Gastroenterology

Research and Practice
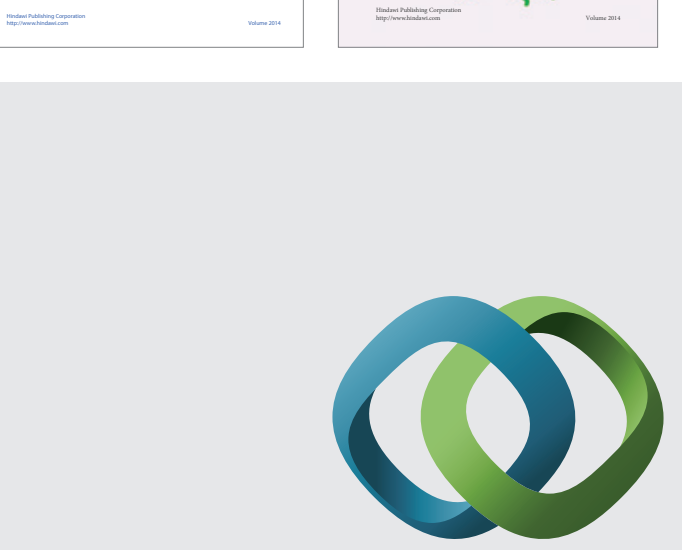

\section{Hindawi}

Submit your manuscripts at

http://www.hindawi.com
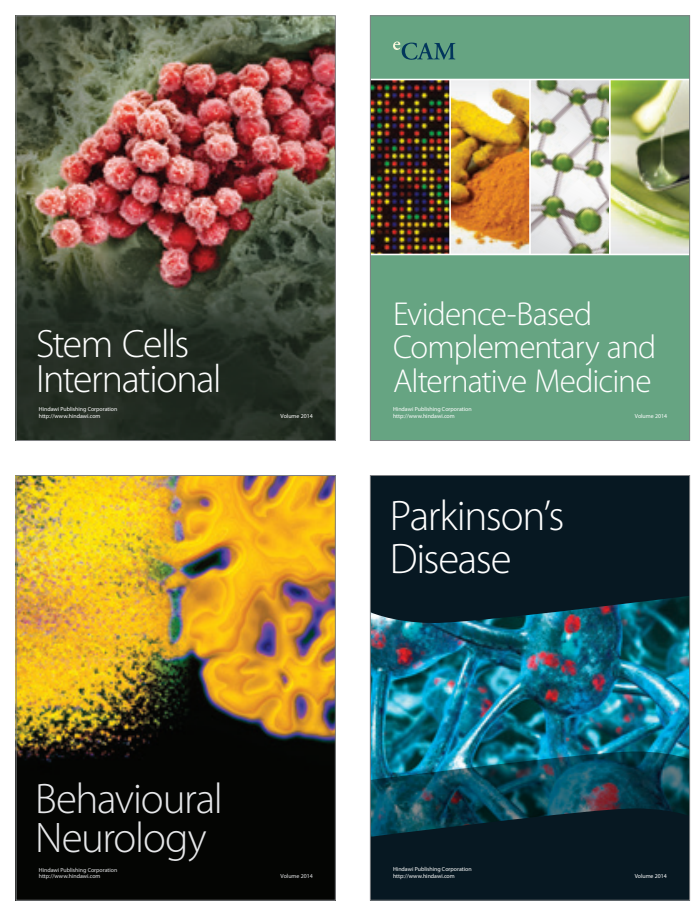

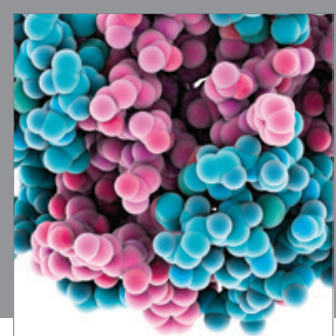

Journal of
Diabetes Research

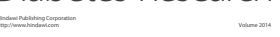

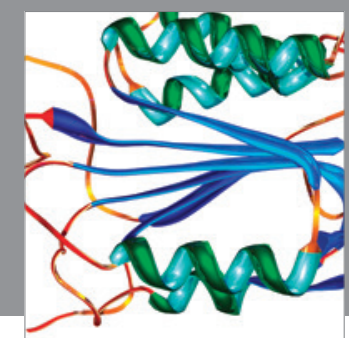

Disease Markers
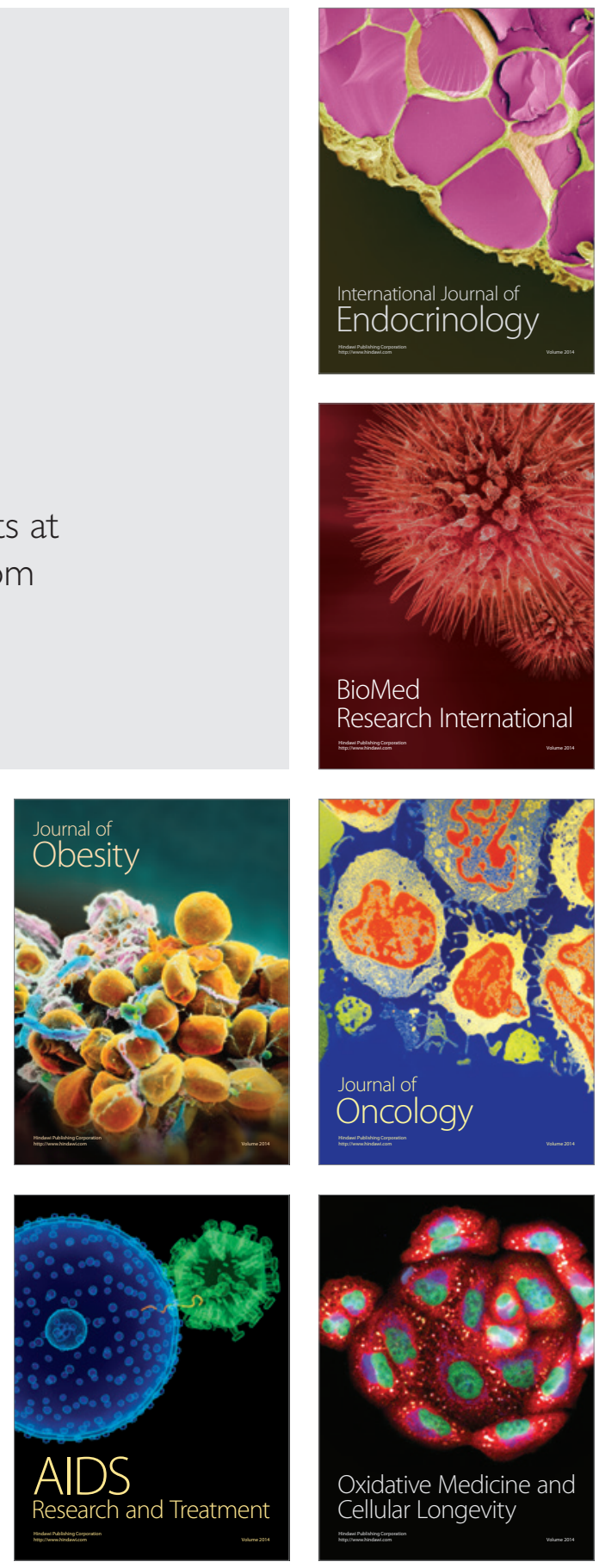